\title{
WORLDDEM - A NOVEL GLOBAL FOUNDATION LAYER
}

\author{
G. Riegler, S. D. Hennig, M. Weber \\ Airbus Defence and Space - GEO-Intelligence, 88039 Friedrichshafen, Germany - \\ (gertrud.riegler, simon.hennig, marco.weber)@astrium.eads.net
}

KEY WORDS: WorldDEM, TanDEM-X Mission, high quality global Digital Elevation Model

\begin{abstract}
:
Airbus Defence and Space's WorldDEM ${ }^{\mathrm{TM}}$ provides a global Digital Elevation Model of unprecedented quality, accuracy, and coverage. The product will feature a vertical accuracy of $2 \mathrm{~m}$ (relative) and better than $6 \mathrm{~m}$ (absolute) in a $12 \mathrm{~m} \times 12 \mathrm{~m}$ raster. The accuracy will surpass that of any global satellite-based elevation model available. WorldDEM is a game-changing disruptive technology and will define a new standard in global elevation models.

The German radar satellites TerraSAR-X and TanDEM-X form a high-precision radar interferometer in space and acquire the data basis for the WorldDEM. This mission is performed jointly with the German Aerospace Center (DLR). Airbus DS refines the Digital Surface Model (e.g. editing of acquisition, processing artefacts and water surfaces) or generates a Digital Terrain Model. Three product levels are offered: WorldDEMcore (output of the processing, no editing is applied), WorldDEM ${ }^{\mathrm{TM}}$ (guarantees a void-free terrain description and hydrological consistency) and WorldDEM DTM (represents bare Earth elevation).

Precise elevation data is the initial foundation of any accurate geospatial product, particularly when the integration of multi-source imagery and data is performed based upon it. Fused data provides for improved reliability, increased confidence and reduced ambiguity. This paper will present the current status of product development activities including methodologies and tool to generate these, like terrain and water bodies editing and DTM generation. In addition, the studies on verification \& validation of the WorldDEM products will be presented.
\end{abstract}

\section{INTRODUCTION}

Digital elevation models (DEM) are key for many commercial and scientific activities, e.g. for analysing and predicting environmental and geophysical processes or events for crisis intervention planning, like flood and risk mapping, for applications in hydrology, forestry, ortho-rectification of multisource geo-data and mapping, infrastructure planning and navigation. In the oil and gas business, for example, elevation information is essential for performing feasibility studies, exploration, development and management of oil and gas fields. The requirements are increasing with respect to availability, coverage, accuracy and homogeneity of elevation information. The quality and reliability of elevation models is of fundamental importance. Today, many DEM products derived from various airborne and spaceborne systems are offered to the market. Large area height information, especially global DEMs, are quite often mosaics of data from various sources with many differing data of different accuracies, resolutions, time differences, formats and projections. The results are hardly uniform and of same quality at each point on Earth (Gantert et al. 2011).

The WorldDEM derived from the TanDEM-X DEM acquired during the TanDEM-X mission, is the first worldwide, pole-topole digital elevation model out of one source. The TanDEM-X mission (TerraSAR-X add-on for Digital Elevation Measurements) was realized in the of a public-private partnership (PPP) between the German Aerospace Center (DLR) and Airbus Defence and Space. Airbus DS holds the exclusive commercial marketing rights for the data and is responsible for the adaptation and refinement of the elevation model to the needs of commercial users worldwide (Riegler 2013).
In this article the TanDEM-X mission concept, the data acquisition and the production of the data to the unique, standardized WorldDEM products is described as well as the validation of the products. Some examples for applications are given.

\section{THE TANDEM-X MISSION}

Primary goal of the TanDEM-X mission is the generation of a world-wide, homogenous digital surface model (DSM) with high precision.

The two satellites TerraSAR-X and TanDEM-X operate as a single-pass SAR interferometer (InSAR) to collect data of the earth's surface. This world's first free-flying high-precision radar interferometer in space operates in a very close formation with distances of a few $100 \mathrm{~m}$ - a technical feat that has never been tried before and that has now been working with perfect reliability for more than four years. Safe operation of this
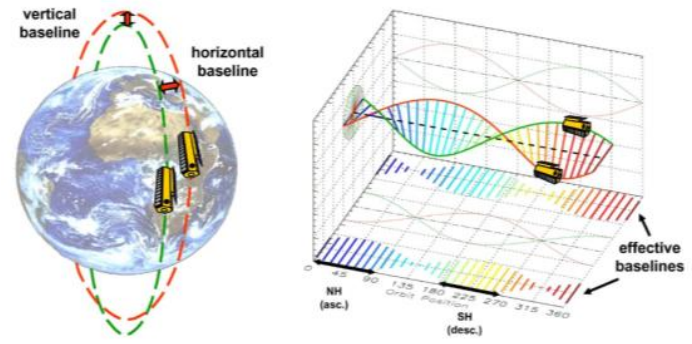

Figure 1. TanDEM-X HELIX Formation; Left: Orbit arrangement; Right: Cross track baselines (function of the orbit position) (Krieger et al. 2007) 
uniquely close coordinated flight of two satellites at an average speed of $28,000 \mathrm{~km} / \mathrm{h}$ is ensured through a Helix formation of the two space crafts (Krieger et al. 2007, Zink et al. 2008).

Mission concept is the completion of the global homogeneous DEM in the shortest possible time frame. To achieve this ambitious goal the acquisition plan is optimized for timeefficient coverage of the Earth's entire landmass. As a result the acquisitions are not recorded region by region but rather in the style of a jigsaw. Seemingly random acquisitions are made in different locations across the globe and piece by piece the jigsaw is completed with the overall picture becoming visible once all pieces are assembled.

For data collection the two satellites operate in the bi-static interferometric StripMap mode. In this mode one satellite transmits the radar signal to illuminate the Earth's surface, while both satellites record the signal's backscattering. This simultaneous data collection avoids possible interferometric data errors due to temporal decorrelation and atmospheric disturbances.

Within four years data over each spot on Earth was collected at least twice. To ensure a reliable homogeneous quality of the global coverage areas with steep terrain and complex land cover like tropical rainforest were covered even three or four times. Latter areas are identified from the previously collected data. For the third and fourth coverage an even more complex satellite operation adjustment was performed. At the start of the TanDEM-X mission the TanDEM-X satellite circled around the TerraSAR-X satellite anti-clockwise. After the satellite swap the direction is now clockwise. This change effects that mountainous terrain is viewed from a different viewing angle to eliminate missing information due to radar effects (Krieger et al. 2007).

The ground segment processing at the DLR is adapted to the phases of the data acquisition schedule. In a systematic data driven processing step all SAR raw data are processed to socalled raw DEMs performed by one single processing system, the Integrated TanDEM Processor (ITP). Key elements of the interferometric processing chain are the timing and phase synchronization as well as instrument corrections, approximation of the bi-static acquisition geometry, high resolution image co-registration, spectral matching of time variant azimuth spectra, unwrapping of steep phase gradients on small scales, and finally consistent geocoding of all product layers (Kosmann et al. 2010).

These raw DEMs are input for the Mosaicking and Calibration Processor (MCP), which produces the DEM. The MCP consists of three components (Wessel et al., 2008):

- Preparation processor: analysis of raw DEMs regarding height discrepancies (e.g. caused by phase unwrapping), water body detection and calibration points extraction. Basis for the calibration are calibration points like reference points and tie-points. Tie-point detection is performed in overlapping areas between the single data takes, which is in minimum four $\mathrm{km}$ wide.

- Calibration processor: setting up all necessary information and parameters for the block adjustment and computing data acquisition height correction parameters for relative and absolute height calibration.
- Mosaicking processor: transfer of all required raw DEMs from the product library to the processing environment. Output layers: height values, height error map, amplitude layer and masks about water, shadow, and layover.

Output is the so-called TanDEM-X DEM, a global Digital Elevation Model. No additional post-processing is applied. SAR specific artefacts due to the terrain or processing artefacts stay untouched.

\section{WORLDDEM}

WorldDEM is the commercial product line product produced by Airbus DS. Based on the TanDEM-X DEM different standardized elevation products are developed and launched to the market.

\subsection{WorldDEM Products}

The WorldDEM product line consists of two DSMs, representing the Earth's surface including heights of buildings and other man-made objects, trees, forests and other vegetation: an unedited and an edited DSM to cope up to various requirements and applications (s. Figure 2).

The unedited DSM product is called WorldDEMcore. In a first step the TanDEM-X DEM is transformed from the ellipsoidal heights (WGS84-G1150 datum) into geoid heights (EGM2008) which is the established reference for most applications. Additionally, the metadata are converted in a format compliant to ISO 19115.

No editing or smoothing is applied to this product. That means all SAR specific artefacts in the terrain, e.g. foreshortening, layover or shadowing, or over water, such as voids or spikes and wells, remain in the WorldDEMcore data. All processing artefacts, e.g. not identical pixels in the overlap area of two geocell borders, are not removed. WorldDEMcore is a product of interest for users with individual specification for certain applications as well as for users who want to do value-adding in-house.

The edited product is the WorldDEM which is produced based on the WorldDEMcore product. The editing of WorldDEMcore is necessary to reduce impacts of SAR-specific data features and artefacts in the elevation model. The WorldDEM editing process can be described in two major steps. The terrain editing step comprises the correction of terrain artefacts caused by SAR specific characteristics (e.g. layover and shadow) or the DSM processing. Since water areas are not representing plausible elevations editing of water bodies is required to produce a high quality elevation model. This second processing step comprises the extraction and editing of water body features according to the WorldDEM editing specifications. For this "hydro editing" of the WorldDEM data, three different types of water body features are defined:

- Ocean: ocean water bodies are set to the elevation height of $0 \mathrm{~m}$, including all seas, inlets, fjords and any other extension of the ocean.

- Lake: This feature class covers all standing inland water bodies (e.g. lakes, reservoirs, fishponds) that are represented by the presence of water in the Amplitude 
Mosaic image. Each lake feature is set to a single elevation.

- River: This feature class represents all Double Line Drain Features such as rivers and canals. Double Line Drains are features with a changing elevation which flows in one direction (monotonic).

Finally the extracted and classified water features are edited. According to its feature type, a water body feature is "flattened" to a single elevation (ocean, lakes) or to monotonic flowing elevations (rivers). The water flattening process includes ensuring that the shoreline elevations of a water body are never below the elevation of the water surface.

The terrain and hydro editing process is followed by a Quality Control (QC). This QC check consists of a combination of automatic tools and visual inspection of the data by an independent operator. This check is a thematic validation and is performed according to ISO 2859.
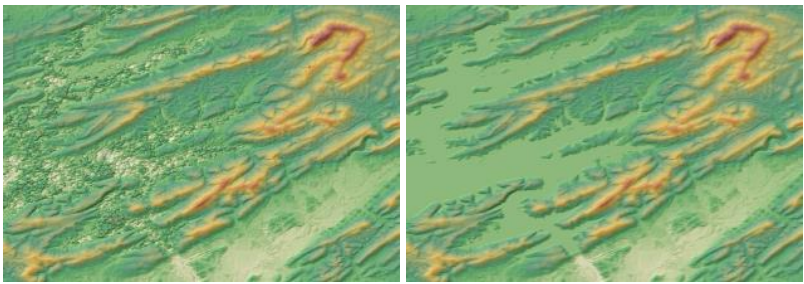

Figure 2. Left: WorldDEMcore (unedited); Right: WorldDEM (edited) Site: Lake Ouachita, Hot Springs, Arkansas, USA

\subsection{WorldDEM Quality and Accuracy}

Within the generation of the TanDEM-X DEM and further processing to the WorldDEM the accuracy and quality of the DEM will be checked in several steps. In the processing of the single raw DEMs a first plausibility check is performed. During the further mosaicking and calibration step reference data are used to assess the quality of the generated DEM product. As reference data in the processing steps SRTM (Shuttle Radar Topography Mission) DEM data and height measurements from the ICESat (Ice, Cloud, and land Elevation Satellite) mission are used (Gruber et al. 2009, Wessel et al. 2009).

A further check of the accuracy is carried out during the production of the WorldDEMcore product. The quality parameters of the TanDEM-X DEM and additional analysis of the delivered quality masks are taken as input for the accuracy assessment.

As during editing to the WorldDEM product artefacts are removed, void areas are filled and water bodies are flattened a final quality assessment and accuracy measurement is carried out after editing and finalization of the product generation.

Due to the cutting edge technologies used for producing the WorldDEM, starting with the data acquisition and data processing performed by DLR and post-processing by Airbus DS including strict quality assurance processes, the high quality of WorldDEM products in terms of homogeneity and accuracy is ensured. The accuracy and level of detail exceed by far the expectations of a $12 \mathrm{~m}$-raster DEM.

The validation results show that the accuracy of the WorldDEM products is even better than determined in DLR's TanDEM-X mission goals. The absolute vertical accuracy is better than $4 \mathrm{~m}$ (linear error 90\%). The specification for WorldDEM is summarized together with the accuracy of the product in Table 1.

\begin{tabular}{|c|c|c|}
\hline \multicolumn{2}{|c|}{ Specification Parameter } & Value \\
\hline \multicolumn{2}{|c|}{ Data type } & 32 Bit, floating \\
\hline \multicolumn{2}{|c|}{ Projection } & Geographic coordinates \\
\hline \multirow{2}{*}{$\begin{array}{l}\text { Coordinate } \\
\text { Reference } \\
\text { System }\end{array}$} & Horizontal & WGS84-G1150 \\
\hline & Vertical & EGM2008 \\
\hline \multicolumn{2}{|c|}{ Pixel spacing } & $0.4 \operatorname{arc~sec}($ approx.12 m) \\
\hline \multicolumn{2}{|c|}{ Vertical Unit } & Meter \\
\hline \multicolumn{2}{|c|}{$\begin{array}{c}\text { Absolute Vertical } \\
\text { Accuracy }\end{array}$} & $\begin{array}{c}<4 \mathrm{~m}(90 \% \text { linear error } \\
\text { based on global product)* }\end{array}$ \\
\hline \multicolumn{2}{|c|}{$\begin{array}{c}\text { Relative Vertical } \\
\text { Accuracy }\end{array}$} & $\begin{array}{c}<2 \mathrm{~m}(\text { slope } \leq 20 \%) \\
<4 \mathrm{~m}(\text { slope }>20 \%) \\
(90 \% \text { linear point-to-point } \\
\text { error within an area of } \\
\left.1^{\circ} \times 1^{\circ}\right) \\
\end{array}$ \\
\hline \multicolumn{2}{|c|}{$\begin{array}{l}\text { Absolute Horizontal } \\
\text { Accuracy }\end{array}$} & $<6 \mathrm{~m}(90 \% \text { circular error })^{*}$ \\
\hline
\end{tabular}

* based on ongoing validation results (TanDEM-X Mission Goal: $<10 \mathrm{~m})$

Table 1. WorldDEM Specification and Accuracy

\section{VALIDATION}

Validation of DEM products is an important topic for the generation of a reliable product specification. Quality assurance of the WorldDEM product is an important factor with a strong focus from Airbus DS side. In order to provide reliable figures an intensive validation campaign is carried out within the product development phase.

A similar campaign has already been performed for the Elevation 10 product, a TerraSAR-X data based elevation model product generated on the basis of radargrammetry (Hennig et al. 2010).

\subsection{Validation Approach}

An increasing number of elevation data providers and new elevation data generation technologies with varying system designs have led to a wide range of accuracies of the data. The lack of a commonly adopted and established validation approach and guidelines, especially for high-resolution and high-accurately DEMs, results in an incomparableness of elevation data from different providers and sources. For elevation data a demanding knowledge of the quality is of required as elevation model are the base layer for further geospatial applications such as ortho-rectification, topographic mapping or surface analysis.

The validation approach of the WorldDEM contains three main steps: (1) visual inspection, (2) profile plot analysis with reference data and (3) a detailed statistical analysis of the absolute vertical accuracy. For the statistical analysis a variety of available reference datasets is used, like SRTM DEM, Lidar DEM and DGPS measurements, depending on availability. Additionally a slope and land cover based analysis is performed (Figure 3). 


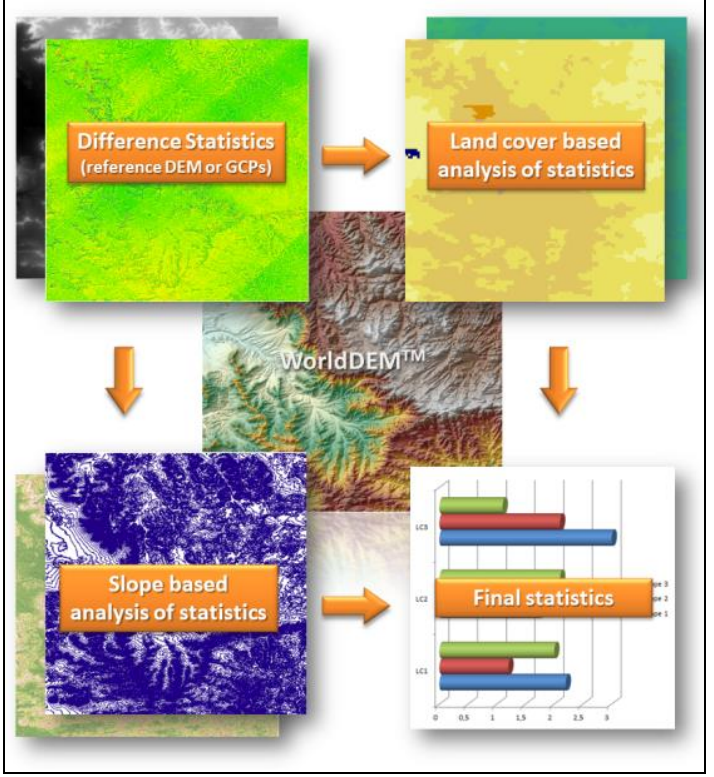

Figure 3. WorldDEM validation approach

\subsection{Validation Results}

For a test site in southern Australia a validation has been performed. The area of interest contains four geocells in a corridor of almost $400 \mathrm{~km}$ length between $131^{\circ}$ and $135^{\circ}$ eastern latitude and $31^{\circ}$ southern longitude. The area is mainly covered by desert with small bushes and trees and some built-up areas in an overall flat terrain (Fehler! Verweisquelle konnte nicht gefunden werden.4).

As reference data the globally available ICESat data have been used. A filtering of the data has been applied in order to remove points over water bodies and with a bad quality flag in the ICESat attributes. The statistical calculations are based on 4516 ICESat points (Table 2).

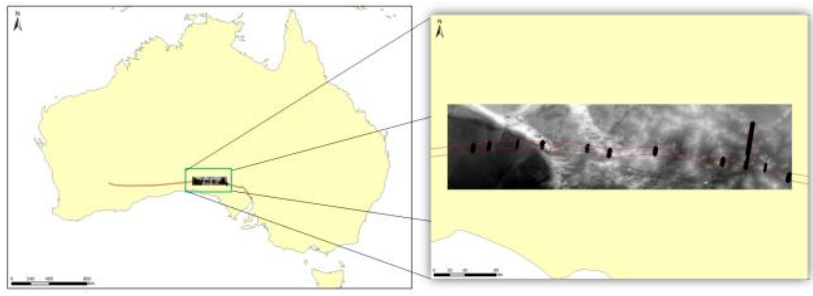

Figure 4. WorldDEM validation approach

\begin{tabular}{c|c}
\hline & {$[\mathrm{m}]$} \\
\hline Mean & -1.3 \\
RMSE & 1.4 \\
LE90 & $\mathbf{2 . 3}$
\end{tabular}

Table 2. ICESat based statistics for the test site in Australia

With an overall accuracy of $2.3 \mathrm{~m}$ Linear Error $90 \%$ (LE90) the absolute calculated accuracy shows much higher accuracy than specified. The result shows, that the specification is based on very conservative values in order to fulfil the accuracy even in areas which are more difficult.

\section{APPLICATIONS}

Digital elevation models are input for a wide range of applications, from image ortho-rectification and base topographic mapping to the more specialized geospatial needs of defence, homeland security, intelligence and military engineering interests. As WorldDEM is globally available as a homogeneous, seamless and high accurate dataset, it provides a new dimension for applications on a global scale (Riegler 2013).

For a variety of topics a globally standardized, homogeneous cross-border dataset is required. Some key application areas are: defence and security, aviation, hydrological modelling oil, gas $\&$ mineral industry and ortho-rectification services.

\subsection{Defence, Security and Aviation}

Worldwide availability of geo-data is of high interest in the field of military actions. Mission planning and in-situ application is typically heterogonous and not standardised depending on governmental actions. Rescuing in case of natural hazards and aviation missions are spread around the globe, independent from administrative areas. For these purposes WorldDEM provides a specified reliable dataset which could be applied around the globe, independent from local data availability.

The example in Figure 5 shows the analysis of WorldDEM data and a land cover layer for potential helicopter landing zones in an area in southern Germany, applicable e.g. for mountain rescuing.

\subsection{Hydrological Modelling}

Another example for worldwide application of a high quality digital elevation model is flooding of rivers and sea level riseup as it happens on all continents. Every year thousands of people die because of flooding. In order to protect humanity the identification of potential flooding areas is important. A high accurate and reliable elevation dataset is essential for the analysis of these areas and will save thousands of lives.

The usage of different elevation datasets for a shoreline analysis is shown in Figure 6. Globally available datasets have been used for the study: (a) WorldDEM, (b) ASTER GDEM (30m) and (c) SRTM (90m). WorldDEM shows the highest accuracy compared to reference data like optical data.

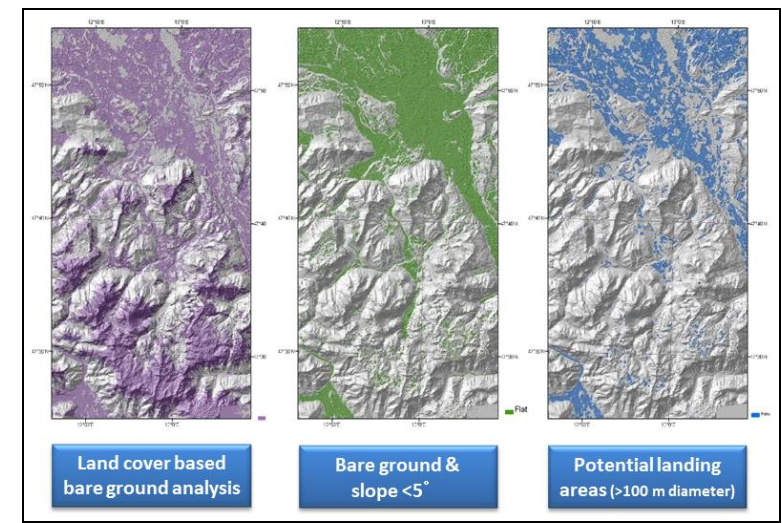

Figure 5. WorldDEM based analysis of potential helicopter landing zones - Area of Berchtesgarden, Germany) 


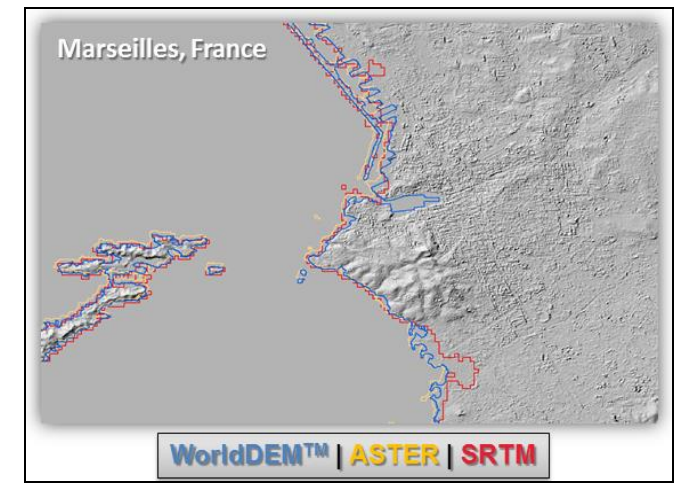

Figure 6. Analysis of shoreline in Marseilles, France based on different DEM datasets

\section{CONCLUSION AND OUTLOOK}

The global availability, high accuracy and level of detail of WorldDEM provide a new standard for applications on global scale. The homogeneity of the WorldDEM products guarantees elevation information without any break or seam lines e.g. along administrative borders, supports standardized processes and yields to comparable results (Riegler 2013).

The WorldDEM product line will be extended by a Digital Terrain Model (DTM) product soon. WorldDEM DTM will represent the elevation of bare earth, vegetation and man-made objects will be removed. Additionally, Airbus DS plans to provide an expanded portfolio of global geo-information layers like Global Ocean Shoreline, Waterbody Map, and Global Airport / Harbour Map based on the WorldDEM data.

\section{REFERENCES}

Gantert S., Riegler G., Teufel F., Lang O., Petrat L., Koppe W. and Herrmann J., 2011. TerraSAR-X, TanDEM-X, TerraSARX2 and their applications. In: APSAR Proceedings 2011, AsiaPacific International Conference on Synthetic Aperture Radar.

Gruber A., Wessel B. and Huber M., 2009. TanDEM-X DEM calibration: Correction of systematic DEM errors by block adjustment. Proceedings of IGARSS 2009, Cape Town, South Africa.

Hennig S., Koppe W., Kiefl N. and Janoth J., 2010. Validation of Radargrammetric Digital Elevation Models Generated with TerraSAR-X Data. 8th European Conference on Synthetic Aperture Radar EUSAR 2010, Aachen.

Kosmann D., Wessel B. and Schwieger V., 2010. Global Digital Elevation Model from TanDEM-X and the Calibration/Validation with worldwide kinematic GPS-Tracks. FIG Congress 2010, Sydney, Australia, 11-16, 2010.

Krieger G., Moreira A., Fiedler H., Hajnsek I., Werner M., Younis M. and Zink M., 2007. TanDEM-X: A Satellite Formation for High-Resolution SAR Interferometry. In: IEEE Transactions on Geoscience and Remote Sensing, Vol. 45, No. 11.

Riegler G., 2013. Astrium Services' WorldDEM Gets Ready. Apogeo Spatial. Fall 2013. Vol. 28, No. 4.
Wessel B., Marschalk U., Gruber A., Huber M., Hahmann T., Roth A. and Habermeyer M., 2008. Design of the DEM Mosaicking and Calibration Processor for TanDEM-X. EUSAR, Friedrichs-hafen, Germany.

Wessel B., Gruber A., Huber M. and Roth A., 2009. TanDEM$\mathrm{X}$ : Block adjustment of interferometric height models. Proceedings of ISPRS Hannover Workshop 2009, Hannover, Germany.

Zink M., Krieger G., Fiedler H., Hajnsek I. and Moreira A., 2008. The TanDEM-X Mission Concept. EUSAR, Friedrichshafen, Germany. 